\title{
Castillo, Manuel Ángel, Mónica Toussaint Ribot y Mario Vázquez Olivera, 2006, Espacios diversos, historia en común. México, Guatemala y Belice. La construcción de una frontera, Secretaría de Relaciones Exteriores, México.
}

E n contraste con el desinterés de las políticas educativas hacia la enseñanza de la Historia, la Secretaría de Relaciones Exteriores financió en 2005 un conjunto de investigaciones sobre la construcción de las fronteras mexicanas. Espacios diversos, historia en común. México, Guatemala y Belice. La construcción de una frontera, forma parte de esa iniciativa. Se trata de un documento historiográfico fundamental para entender el presente de Chiapas y de la región fronteriza del sur y sureste de México, a partir de las cambiantes relaciones con sus vecinos, desde el momento en que nuestro país se declaró independiente.

Manuel Ángel Castillo, Mónica Toussaint Ribot y Mario Vázquez Olivera son destacados investigadores de El Colegio de México, El Instituto Mora y la UNAM respectivamente, especialistas en los estudios de las relaciones sociales y políticas por las que han transitado México y los países centroamericanos. En este libro nos acercan a la frontera sur-sureste, bastante desconocida aun para los especialistas. El premio a la mejor investigación que el Instituto Nacional de Antropología e Historia otorgó a sus autores a fines de 2007 nos parece un merecido reconocimiento.

La visión histórica regional y transfronteriza es el primer rasgo digno de mención, pues al sintetizar, articulary enriquecer con investigaciones documentales y de archivo de primera manouna gran cantidad de estudios temáticos, locales o parciales (de autores como Jan de Vos, Louis Benjamín, Lorena Careaga, Michel Foucher, Diana Guillén) nos proporcionan por primera vez una visión regional de conjunto sobre los sucesos más significativos para la definición de nuestra frontera durante los dos últimos siglos, desde el Pacífico hasta el Mar Caribe, atravesando Chiapas, Campeche, Tabasco y Quintana Roo.

La visión geopolítica de los encuentros y desencuentros en el interior de los estados fronterizos y entre ellos es el eje principal de la investigación. La definición de los límites fronterizos nacionales en la primera mitad del siglo XIX fue un problema fundamental para los países latinoamericanos, pues la delimitación del espacio nacional definiría la extensión en la cual cada Estado habría de realizar su propio proyecto de soberanía e identidad en función del aprovechamiento de los recursos, el trabajo y la dinámica del poder, basados en la acumulación y expansión del capital.

En ciertos momentos las fronteras se han conformado como límites controlados debido a las políticas nacionalistas y a la protección de los mercados internos, las epidemias, etcétera. En la actualidad los límites fronterizos, a pesar de las políticas de "Seguridad Nacional" de Estados Unidos, han sido desbordados por el tráfico del libre comercio y la creciente migración.

Los procesos de articulación y desarticulación fronteriza plantean a los autores el interrogante de si 
se habla de una sola región sur-sureste o si se trata de varias regiones; el nombre del libro refleja esta preocupación, pues su contenido da elementos a los lectores para interesarse en el problema por el estudio de las relaciones políticas, muchas veces tensas de nuestro país con los países vecinos del sur y sureste.

\section{Estructura del libro y características generales}

En las 285 páginas del libro, distribuidas en un prefacio, una introducción, siete capítulos temáticos, un epílogo y fuentes, se advierte una cuidadosa edición y cierto lujo, pero lo que más impresiona son las numerosas fotografías seleccionadas hábilmente por los autores.

Otra característica es el cuidado de ubicar espacialmente la historia regional con numerosos mapas que permiten tener presente que la historia de los pueblos y el interés de gobiernos y empresarios, así como sus disputas, se inscriben en territorios específicos y cambiantes. La colección de mapas es de una riqueza cuyo valor (como observó Jan de Vos en su presentación del libro en San Cristóbal de Las Casas) se minimiza, porque el tamaño de las reproducciones impide su lectura; los editores los han tratado como unailustración más y no como documentos históricos básicos en el enfoque geopolítico. Valdría la pena que los autores los publicaran como parte de una cartografía histórica del estado.

Cada ilustración lleva al pie un texto con dos partes: una referida a los contenidos de la ilustración y otra explicativa, sacada del cuerpo textual. La sola lectura de las ilustraciones y sus textos permite un seguimiento de los hechos sobresalientes.

Cabe mencionar el enriquecimiento historiográfico que hacen los autores a través de sus investigaciones en los archivos nacionales y extranjeros de Guatemala y Estados Unidos, mencionados en la sección de "Fuentes". Además de sistematizar la historia regional aportan información nueva que permite conocer las disputas entre los países, las regiones fronterizas y los diferentes sectores de la población de los dos lados de la frontera.

\section{Contenido de los capítulos}

Capítulo l: "Gestación de la Frontera": examina las primeras etapas de conformación de las fronteras nacionales a partir de la Independencia, en particular las alteraciones, entre 1821 y 1842, de los linderos que separaban el virreinato novohispano de Guatemala. Se explica la disputa por Chiapas y el Soconusco como resultado, por parte de autoridades y dirigentes políticos de México y Centroamérica, de distintos proyectos de integración nacional. Se reseñan las concepciones y planteamientos del Estado mexicano acerca de las regiones fronterizas del sureste.

Capítulo 2. "Fronteras en Vilo": se abordan los procesos políticos y sociales durante la segunda mitad del siglo XIX: la peculiar y conflictiva relación con Guatemala en el caso de Chiapas; el estallido de la Guerra de Castas en Yucatán y la apropiación de la frontera con Belice por los mayas rebeldes a lo largo de medio siglo, así como la apertura de la Selva Lacandona a la explotación maderera.

Capítulo 3. "Fronterasy Diplomacia”: analizalas disputas territoriales entre Méxicoy Guatemala por Chiapasyel Soconusco; se revisan las negociaciones diplomáticas que tuvieron lugar en la Ciudad de México y en Washington. Destaca la figura de Matías Romero y sus intereses económicos en la región del Soconusco para lograr la firma del Tratado de Límites en 1882. Se explica de manera detallada la negociación con Gran Bretaña y el proceso para establecer la frontera de México con Belice en 1893.

Capítulo 4. "Fronteras entre dos Tiempos": se destacan losintereses de las compañías madereras en la delimitación fronteriza; se detallan las dificultades enfrentadas por la Comisión de Límites por las imprecisiones cartográficas y los conflictos entre los comisionados de cada país. Se revisan las disputas fronterizas, que culminan con la firma de un tratado entre México y Guatemala en 1895. También el desarrollo económico, social y cultural de la frontera quintanarroense es foco de atención, con hincapié en la constitución del territorio y la fundación de Payo Obispo, ahora Chetumal, en los primeros años del siglo XX. Se revisa el período de entre siglos en Chiapas, Quintan Roo,

154 Revista LiminaR. Estudios sociales y humanísticos, año 6, vol. VI, núm. 1, junio de 2008, Tuxtla Gutiérrez, Chiapas. ISSN: 1665-8027 
Tabasco y Campeche en lo relativo al proceso político, el impulso económico y el desarrollo cultural, para culminar con el impacto del proceso revolucionario en 1910.

Capítulo 5. "Linderos, Gente y Territorios": se hace un recuento general de las transformaciones que experimentaron las regiones de la frontera y la interacción con Belice y Guatemala a partir del establecimiento del régimen revolucionario. Se examinan las principales pautas y contratiempos de la incorporación de aquellas áreas del país a los cambios que propició la revolución y cómo, durante largo tiempo, en aquellos territorios dominaron las dinámicas localesy losintereses privados que se consolidaron durante el Porfiriato hasta que, a mediados de los años treinta, el Gobierno Federal impulsó una audaz política reformista con importante efecto en las áreas fronterizas.

Capítulo 6. "iHacia una Nueva Dimensión Fronteriza?": se analizan los procesos sociales en la historia reciente de la región: su poblamiento, el impacto de los grandes proyectos de desarrollo y el efecto de la construcción de infraestructura. Se señala la importancia del proceso de expansión de la frontera agrícola del país, el auge de los cultivos de exportación como eje de desarrollo de algunas zonas de la frontera y de los incipientes pasos hacia la integración económica transfronteriza. Se analiza la movilidad de la población dentro y fuera de la región. También se hace un señalamiento sobre la dimensión ambiental por las repercusiones que su modificación pueda tener en un espacio mayor. Por último, se subraya la importancia de la dimensión geopolítica de la frontera, pues dicha región ha pasado a ocupar un lugar preponderante en la agenda nacional y en la internacional.

\section{Posicionamiento y enfoque metodológico}

Señalan los investigadores que en la economía y en las expresiones culturales las fronteras son depositarias de capacidades y acervos que materializan los alcances del quehacer de sus poblaciones; la visión geopolítica de la construcción histórica de los Estados nacionales y sus fronteras evidencia un posicionamiento que prioriza las relaciones de poder entre México y sus vecinos, cuya soberanía existe "en un contexto definido por un amplio margen de situaciones asimétricas" presentes en la dinámica capitalista del sistema.

Las relaciones desiguales entre las naciones transforman el significado de las fronteras, como lo muestran los procesos mundiales de liberación de los mercados en las últimas décadas, originando una violenta einjusta transnacionalización de los recursos, de los capitales y del trabajo, y propiciando un serio cuestionamiento del papel de las fronteras y del significado original de la soberanía.

La metodología para el análisis de fronteras debe dar cuenta de las desigualdades, asimetrías y complementariedades en un entorno regional transfronterizo amplio, y abandonar la idea de que la frontera es "el confín", implícita en las visiones nacionalistas. Esta dimensión transfronteriza permite captar la heterogeneidad y variabilidad de las características sociales en un espacio de más de 1300 kilómetros de largo, e incluye necesariamente la conformación ecológica, complejo de entornos ambientales, nichos de biodiversidad y contenedora de los recursos naturales. El sureste mexicano es un ámbito de gran biodiversidad, "fuente no sólo de sustentación de su población, sino del enriquecimiento de no pocos explotadores de sus recursos de acuerdo con las posibilidades de realización en los mercados nacionales e internacionales".

En décadas recientes la inversión de capitales transnacionales en la captación y explotación de los recursos energéticos ha orientado las políticas gubernamentales hacia la construcción de sistemas hidrológicos, vías de comunicación y redes de servicios trasnacionales que han influido en las dinámicas fronterizas, aunque "no siempre han redundado positivamente en beneficio de su población", dado el sistema de polarizaciones que caracteriza el proceso de globalización.

El análisis estadístico al final de la introducción metodológica muestra la lenta y fragmentada ocupación del territorio fronterizo del sur de México. En los inicios del siglo XX las entidades fronterizas apenas alojaban el 4.5\% de la población del país, proporción que se man- 
tuvo baja a lo largo del siglo XX. Recientemente han empezado a cambiar las pautas demográficas a pesar de los altos niveles de marginación y pobreza asociados con bajos ingresos, deficiente alimentación, limitado acceso a los servicios de salud, educación y programas de capacitación para el trabajo.

Nos parece importantela interrelación que la metodología establece entre lo social y lo personal; la riqueza de las relaciones transfronterizas reside en las vinculaciones cotidianas entre las comunidades asentadas en uno y otro lado de la frontera porque hacen posible la construcción de las identidades de pertenencia y de relación. Pero los autores consideran que "la definición de los límites debe verse como un punto de llegada, las más de las veces de naturaleza temporal, sujeta a enmiendas y redefiniciones, justamente por la naturaleza social del proceso".

En cada etapa analizada se toman en cuenta las políticas de inclusión-exclusión implementadas por el Gobierno mexicano; esto queda explícito en algunos episodios que se analizan con detalle: la anexión de Chiapas y el Soconusco a México, la guerra de sometimiento de los rebeldes mayas de Chan Santa Cruz y, más recientemente, la "Guerra del Camarón".

Desde nuestra experiencia de investigación antropológica percibimos que, sin ser contradictorias, existen diferencias entre las metodologías de la historia y de la sociología, determinadas por las fuentes de información y los tiempos de los sucesos. La historia recurre a información documental como fuente primaria, mientras que la sociología dispone de fuentes vivas y actuales que hacen posible la visión integral de los procesos. En el amplio enfoque que se expone para la investigación histórica de la frontera sur-sureste predomina el carácter integrador de los enfoques sociológicos de las corrientes neoestructuralistas; esto porque se plantea interrelacionar los aspectos ecológicos (económicos y políticos principalmente) con las expresiones simbólico-cultural e identitaria que son parte de las "estructuras estructurantes" (comoles llama Bourdieu) de la sociedad. La puesta en práctica de esta metodología tiene importantes ventajas y desventajas para un estudio como el que se presenta en Espacios Diversos, Historia Común. Las ventajas podrían ser mayores para el estudio de los procesos recientes y actuales. De cualquier manera el enfoque integrador resulta positivo y necesario en la historia, pues ayuda a sopesar los aspectos que aún quedan por estudiar.

Vale la pena comentar la diferencia en el énfasis que se otorga al significado político de los acontecimientos; en tanto que los asuntos del pasado se muestran con una posición crítica fundamentada en las profundas contradicciones entre los países, el análisis de los sucesos de fines del siglo XX poco nos dice sobre la crudeza y endurecimiento de algunas políticas norteamericanas que presionan desde una posición de poder a los gobiernos subordinados. Tampoco se profundiza en el papel que el Estado mexicano ha tenido en la reproducción de esta dinámica imperialista que ha acentuado las asimetrías sociales y la violación a los derechos humanos en la región, como sucede con el trato cruel y violatorio de los derechos humanos que reciben los migrantes guatemaltecos en $\mathrm{La}$ Rivera Maya y los transmigrantes centroamericanos al cruzar la frontera y a su paso por el territorio mexicano.

Quizá el aporte más significativo, desde el punto de vista social, es la referencia de los autores a los objetivos de su investigación: contar con un conocimiento histórico integral y serio para "combatir los mitos y creencias sin fundamento de muchas afirmaciones inconsistentes sobre la frontera, que impiden entender a cabalidad la complejidad y orígenes de las situaciones conflictivas, como las que se han presentado recientemente en algunos lugares de la región"; carencia que "limita la generación de soluciones adecuadas a las necesidades de los pobladores de la frontera". Conocer la historia para dar fundamento a las acciones políticas que tomen en cuenta a la población es un paradigma muy valioso que subyace en esta investigación.

Mercedes Olivera
CESMECA-UNICACH CESMECA-UNICACH Línea de investigación: género y migración 